ISBN 978-81-933894-1-6

2017 International Conference on Studies in Business Management, Law and Education

(SBMLE-17)

Kyoto (Japan) April 20-21, 2017

\title{
Awareness of Apt Computer Use and Hazards among University Students in Dhaka
}

\author{
Rubayat Kabir \\ East West University, Dhaka, Bangladesh.
}

\begin{abstract}
Purpose: To accomplish Digital literacy in Bangladesh, educational institutions; starting from primary schools to universities facilitates the process of acquiring knowledge in information and communication technology (ICT). This adds in obtaining a competitive advantage over others. This paper obtains an overview of Computer Ergonomics and Musculoskeletal Disorder (MSD). It also assesses baseline awareness about appropriate ways of using computers among the students. And to see whether any kind of body discomfort occurs due to computer use.

Methodology: A cross sectional survey was performed using a self- administered questionnaire among $1^{\text {st }}-12^{\text {th }}$ semester students. A total of 280 students were approached for the survey out of which 256 surveys were taken into consideration. The respondents were from 14 different Universities in Dhaka.

Result: Findings reveal that the percentage of students using laptop is considerably high. Many respondents mentioned about feeling certain body discomfort while using Personal Computers (Pc's). Moreover, the awareness of appropriate ways of using computers is very bleak. And, as a result they do not practice the needed posture while using their devices.

Implication: From the findings it can be remarked that there is scope of improvement in the curriculum design of the computer courses to incorporate healthy computing components. Increasing awareness and to emphasize on its practice could reduce the risk factors for musculoskeletal discomfort and build sustainable habit among the next working generation.
\end{abstract}

Keywords: Computer Ergonomics, Body discomfort, Musculoskeletal disorder, MSD, Computer use.

\section{Introduction}

The recent development in technology is changing the way we look at our lives. The massive shift in the mode of learning and communicating has revolutionized a lot of day to day activities. Businesses in this case serve no exception. It is estimated that about $47 \%$ of all jobs in the United States are at risk of computerization [1]. And around $65 \%$ of children entering primary school today will work in completely new job types that don't yet exist [2].

In the education sector, the traditional form of books has been replaced by electronic books which is nothing but in its digital format [3]. However, there are debates about its definition. To keep up with these changes the workers of the future has to be even more ready than before. For this attainment, educational institution's facilities also require attention, especially in the developing countries. To obtain educational attainments, Information and Communication Technologies (ICTs) as a tool has attracted both policy makers and academic researchers [4]. There are about 37 public and 92 private universities and 3 international universities [5].

So as to say, the major drawback of the inappropriate and over use of such devices causes several discomfort. This area of study has been on concentration for many disciplines. According to International Ergonomics Association [6] "Ergonomics (or human factors) is the scientific discipline concerned with the understanding of 
interactions among humans and other elements of a system, and the profession that applies theory, principles, data and methods to design in order to optimize human well-being and overall system performance." The word ergonomics is derived from the Greek word ergon meaning work and nomos meaning law [7]. In this case, the use of computer related device we categorize as computer ergonomics.

Extended work for long periods can adversely lead to musculoskeletal disorders (MSDs) if the ergonomic design is improper [8]. Repetitive works and awkward motion of the fingers, hands and wrists, have been proposed as possible cause of injury related to the prolonged use of the keyboard and mouse [9].

It is estimated that, globally, musculoskeletal conditions has increased by 25 percent over the past decade [10]. It is also expected that developing countries will be spending around 25 percent of health expenditure on trauma-related care by the year 2010 [11]. Disseminating proper educational intervention improves its knowledge and practice which is assumed to reduce the associated health risk factors [12].

\section{Literature Review}

In a study by Reference [13] on musculoskeletal functional impairment associated with computer use among college students, it was found that upper extremity pain was experienced by 10 percent of undergraduates within an hour of computer use. In support of this view, Reference [14] assessed computing posture among college students and noticed graduate students who use computer for over 10 hours a week felt musculoskeletal pain within the $1^{\text {st }}$ hour of computer use.

To focus on the issue of musculoskeletal discomfort, Reference [15] stated that the most discomfort experienced in the undergraduate laptop users was in the shoulder and the least mentioned discomfort experienced was in elbow accounting for over 75 percent and 37 percent respectively. To add to this, Reference [16], reported that among the $2^{\text {nd }}$ year university students, neck pain was a common factor. The reason that led to this discomfort was usually because of the inappropriate positioning of the computer screen and the keyboard while using it. Moreover, in another study conducted by Reference [17], regarding the prevalence of computer related musculoskeletal Pain, it was noted that about 88 percent of the respondents complained about musculoskeletal pain among which female students on a comparative basis had more complains than the male students.

To note down the variation in activity among children and yound adults, Reference [18] presented us that children tended to show more spinal flexion, variation in posture and muscle activity than did the adults.

Moreover, in the assessment of students, Reference [19] found that over 50 percent of the student users do not have adequate knowledge about positioning of computer workstations. To support this viewpoint, Reference [20] reported that more than 35 percent of the students using Tablet PC at home would not utilize a desk or table. And over 50 percent of the students experienced discomfort in eyes, neck, head, wrist and back.

Reference [21] reported the major findings of a participatory ergonomics training program. It was observed that there was a reduction in discomfort and increase in the behavior of taking rest breaks among notebook user from pre- and post-survey. However, in an attempt to study on computer related symptoms, Reference [22] found no correlation between the numbers of hours worked and experience of discomfort for college going students. Nevertheless, 81 percent of the participants mentioned doing something to reduce their discomfort while working.

\section{Methodology}

A cross sectional survey was executed to a total number of 280 students out of which 256 surveys were taken into consideration. Among them 56 percent were male respondents and 44 percent were females respondents. Few questions were set related to computer ergonomics awareness and its associated factors. It was thus pilot tested to 27 students belonging to different subjects and different semesters. After the alterations made from the pilot study, it was administered to the participants. The age group of the respondents was between 18- 
28 years, belonged as early as $1^{\text {st }}$ to $12^{\text {th }}$ semester. However, majority of the students fell in between $2^{\text {nd }}-7^{\text {th }}$ semester. The questionnaire was administered to 25 of them online, and the rest of them were face to face. The respondents were from 14 different Universities of Dhaka. Among them, 34 percent were from the Business faculty, 36 percent were from the Social Sciences and 30 percent were from the faculty of Science and Engineering. Amid them around 13 percent was either working part time or full time.

\section{Discussion}

When asked to these participants about the ICT devices they use, about 91.7 percent mentioned that they use mobile phone, which was expected. The next in line was 55.1 percent who said they use laptop, about 44.9 percent mentioned that they use desktop and lastly 14.8 percent mentioned that they use tablet. From the current statistics all over the world, the progression in percentage seemed to match.

While answering about awareness of apt posture regarding the use of devices, maximum of them replied that they did not know it. About 59.4 percent said that using their Pc's they choose to their table and chair. However, 23.4 percent of them reported using their Pc's by lying down on bed or any place comfortable, for e.g. sofa. Few of them; 5.9 percent stated that based on their convenience they resort to both the postures.

For using their Pc's, maximum of them reported that they felt discomfort either most of the time or some of the times. About 35.2 percent of them said discomfort was felt most of the time. And 33.2 percent mentioned they sometimes feel discomfort. However, it was constructive to know that 31.6 percent reported that they do not feel any kind of discomfort.

Table I. Body Discomfort Types and the Strategies Used

\begin{tabular}{cccc}
\hline \hline Body Discomfort Type & Percent & Way to Reduce Discomfort & Percent \\
\hline Back pain & 35.5 & Take rest & 39.5 \\
Eyes discomfort & 14.1 & Doesn't do anything & 23.8 \\
Neck pain & 7.8 & Exercise & 16.0 \\
Wrist pain & 2.7 & Stop using & 6.6 \\
More than one reason & 6.6 & Change posture & 2.3 \\
\hline \hline
\end{tabular}

Table I shows percentages related to the kinds of discomfort felt while using their Pc's and the strategies to overcome the discomfort. Regarding body discomfort, the highest reported factor was related to back pain that accounted for almost 35 percent and the lowest reported discomfort was that of wrist pain which constitutes of almost 3 percent. When asked to these respondents about their strategies to reduce the stated discomfort, maximum of the respondents answered that when they feel discomfort, they on a usual basis resort to taking rest. About 39 percent said so. Nevertheless, it was interesting to find out that nearly 24 percent of them did not do anything while feeling discomfort. Another strategy mentioned by these respondents was to exercise. In this case, some of the things that they do is; walking, moving their neck either clock or anti clockwise, or do some hand exercises. However while reviewing the literature we saw evidence of students complaining more of the neck pain than any other body parts [16].

These respondents were again enquired concerning their awareness of appropriate posture while using Pc's. Notably about 80 percent mentioned that they were unaware about it. To cross check the same question, the respondents was asked by using different wordings. The phrasing of the question was whether they were aware of the term ergonomics. Around 12 percent said that they were aware. In between them 11 percent mentioned that they heard the term from a friend. And the rest of them that is about 2 percent said they heard the term from a friend or their course. The 12 percent of the respondents that reported about knowing the term ergonomics, among them, only 41 percent mentioned about practicing it. 


\section{Conclusion}

It has been observed that the body discomfort is faced by a lot of students studying in varied semesters. This might have an effect on the individual's quality of the output. However the self-administered survey is unable to determine the exact magnitude of pain and its associated factors. The results verified a considerable lack of awareness of the concept of computer ergonomics among these students. Therefore awareness programs on risk factors and appropriate practice are vital in order to prevent and remediate this condition. Nonetheless it has been noted that many of them adhere to taking rest breaks and also do some sort of exercise when they feel discomfort. If these students are trained in more appropriate manner, that is, when and what exercises to do or when to take rest or even how to place their Pc's in front of them, this could assist in reducing discomfort. Effort should be made to empower computer users within the university on computer ergonomic principles, so as to prevent the occurrence of work-related musculoskeletal complaints that can arise from improper use of computers.

\section{Acknowledgements}

I am truly grateful to the students of SOC 202: Social Psychology of the Department of Social Relation, spring 2017, East West University, who has actively participated in the task. I am thankful to Dr. Marzia Zaman Sultana, Ms. Alima Nusrat and Mr. Ishrak Kabir for their assistance in completion of the paper. I feel obliged to Dr. Rafiqul Huda Chaudhury for his enormous encouragement to engage in research. Also my colleagues and mentors Prof. Bijoy P. Barua, Dr. Parveen Haque, Ms. Touhida Taslima, Dr. Lutfun Nahar, Mr. Sanaul Mondal, Mr. Shahriar Khandakar, Ms. Sifat E Sultana, Ms. Azrin Afrin, Dr. Anisur Rahman Khan and Dr. Fouzia Mannan for their guidance. And I appreciate the efforts of East West University for supporting our research activities. And I appreciate the efforts of East West University for their support towards research activities.

\section{References}

[1] C. B. Frey and M. A. Osborne. (September 2013). The future of employment: how susceptible are jobs to computerisation?. Available www.oxfordmartin.ox.ac.uk/downloads/academic/The_Future_of_Employment.pdf

[2] World Economic Forum, The Future of Jobs. Employment, Skills and Human Capital Global Challenge Insight Report, 2016. Available http://www3.weforum.org/docs/Media/WEF_FutureofJobs.pdf

[3] J. S. Lin and W. L. Huang, (2011). Research in the use of eBook and M Learning. Journal of Engineering Technology and Education, 7(5), pp. 862-868.

[4] V. Spiezia, (2010). Does Computer Use Increase Educational Achievements? Student-level Evidence from PISA. OECD Journal: Economic Studies, 2010(1), pp. 1-22, doi:10.1787/eco_studies-2010-5km33scwlvkf https://doi.org/10.1787/eco_studies-2010-5km33scwlvkf

[5] University Grants Commission of Bangladesh, List of Universities 2017, 2017. Available www.ugc.gov.bd/en/home/university.

[6] International Ergonomics Association. Definition and Domains of ergonomics 2014. Available http://www.iea.cc/whats

[7] R. A. Rwamamara and J.J. Smallwood, Ergonomic in Construction, Specifically in Industrially Developing Countries. In Scott, P. A (Eds.), Ergonomics in Developing Regions: Needs and Application, NW, USA: CRC Press, 2009, pp. 314-321.

https://doi.org/10.1201/9781420079128.ch19

[8] M. S. Sirajudeen, P. S. Pillai and G. M. Y. Vali, (2013). Assessment of Knowledge of Ergonomics among Information Technology Professionals in India. International Journal of Health and Rehabilitation Sciences, 2(4), pp. 192-197.

[9] J. Village, D. Rempel and K. Teschke, (2005). Musculoskeletal disorders of the upper extremity associated with computer work: a systematic review. Occupational Ergonomics, 5(4), pp. 205-218.

[10] WHO (World Health Organization). Global Programme on Evidence for Health Policy Discussion. Global burden of disease, 50, 2000.

[11] I. Y. Y. Tsou and H.H. Chng, (2002). The Bone and Joint Decade 2000-2010: For Prevention and Treatment of Musculoskeletal Disease, 31(1). 
[12] G. Hultman, M. Nordin, and H. Saraste, (1995). Physical and psychological workload in men with and without low back pain. PubMed, 27(1), pp. 11-7. Available http://www.ncbi.nlm.nih.gov/pubmed/7792545

[13] N. Hupert, B.C. Amick, A.H. Fossel, C.M. Coley, M.M. Robertson and J.N. Katz, (2004).Upper extremity musculoskeletal symptoms and functional impairment associated with computer use among college students. Work, 23(2), pp. 85-93.

[14] C. C. Men’endez, B. C. Amick, C., R. B. Chang, Harrist, M. Jenkins, M. Robertson and J. N. Katz, (2009). Evaluation of two posture survey instruments for assessing computing postures among college students. Work, 34, pp. 421-430. doi:10.3233/WOR-2009-0942.

[15] A. O. Obembe, O.E. Johnson, T.O. Tanimowo, A.T. Onigbinde and A.A. Emechete, (2013). Musculoskeletal pain among undergraduate laptop users in a Nigerian University. Journal of Back and Musculoskeletal Rehabilitation. 26(4), pp. 389-395, doi:10.3233/BMR-130397.

https://doi.org/10.3233/BMR-130397

[16] S. Kanchanomai, P. Janwantanakul, P. Pensri and W. Jiamjarasrangsi, (2011). Risk factors for the onset and persistence of neck pain in undergraduate students: 1-year prospective cohort study. BMC Public Health, 11(1). doi:10.1186/1471-2458-11-566.

https://doi.org/10.1186/1471-2458-11-566

[17] V. Rajagopal, R.M. Rosli, P. Rintai, N. Rustim, R. Benadus and Usai, W. (2012). The Prevalence of ComputerRelated Musculoskeletal Pain Among College Students-a Cross -Sectional Study. American Medical Journal, 3(1), pp. 33-36.

https://doi.org/10.3844/amjsp.2012.33.36

[18] B. Maslen \& L. Straker. (2009). A comparison of posture and muscle activity means and variation amongst young children, older children and young adults whilst working with computers. Work, 32(3), pp. 311-320. doi: 10.3233/WOR-2009-0829

[19] P. Joshi, I. Karki and P. Sharma, (2015). Computer workstation ergonomics: knowledge testing of State Agricultural University (SAU) students. J Hum Ecol, 49(3), pp. 335-339.

[20] C. M. Sommerich, S. A. Lavender, J. A. Buford, J. J. Banks, S. V. Korkmaz and W. S. Pease, (2007). Towards development of a nonhuman primate model of carpal tunnel syndrome: Performance of a voluntary, repetitive pinching task induces median mono neuropathy in Macaca fascicularis. Journal of Orthopaedic Research, 25(6), pp. 713-724. doi:10.1002/jor.20363

https://doi.org/10.1002/jor.20363

[21] K. Jacobs, P. Johnson, J. Dennerlein, D. Peterson, J. Kaufman, J. Gold, . . M. Pencina, (2009). University students' notebook computer use. Applied Ergonomics, 40(3), pp. 404-409. doi:10.1016/j.apergo.2008.11.009.

https://doi.org/10.1016/j.apergo.2008.11.009

[22] E, Peper and K.H. Gibney, "Computer Related Symptoms: A Major Problem for College Students. In AAPB (Ed.), in Proc. Thirteenth Annual Meeting of the Association for Applied Psychophysiology and Biofeedback, Wheat Ridge, 1999, pp. 119-122. 